\title{
Patient Safety in the World
}

\author{
Neelam Dhingra-Kumar, Silvio Brusaferro, \\ and Luca Arnoldo
}

\subsection{Introduction}

"First, do no harm," the principle of nonmaleficence, is the fundamental principle to ensuring safety and quality of care. Patient safety is defined as the prevention of errors and adverse effects associated with healthcare.

The global movement for patient safety was first encouraged in 1999 by the report of the Institute of Medicine (IOM) "To err is human." Although some progress has been made, patient harm is still a daily problem in healthcare systems around the world. While long-standing problems remain unresolved, new, serious threats are emerging. Patients are getting older, have more complex needs and are often affected by multiple chronic diseases; moreover, the new treatments, technologies and care practices, while

N. Dhingra-Kumar

WHO Patient Safety Flagship: A Decade of Patient

Safety 2020-2030, Geneva, Switzerland

e-mail: dhingran@who.int

S. Brusaferro

University of Udine, DAME, Udine, Italy

Italian National Institute of Health, Rome, Italy

e-mail: silvio.brusaferro@uniud.it

L. Arnoldo $(\bowtie)$

University of Udine, DAME, Udine, Italy

e-mail: luca.arnoldo@uniud.it having enormous potential, also offer new challenges. To guarantee the safety of care in this context, the involvement of all stakeholders, including both healthcare professionals and patients, is needed together with strong commitment from healthcare leadership at every level.

\subsection{Epidemiology of Adverse Events}

Available evidence suggests hospitalizations in low- and middle-income countries lead annually to 134 million adverse events, contributing to 2.6 million deaths. About 134 million adverse events worldwide give rise to 2.6 million deaths every year. Estimates indicate that in high-income countries, about 1 in 10 patients is harmed while receiving hospital care. Many medical practices and care-associated risks are becoming major challenges for patient safety and contribute significantly to the burden of harm due to unsafe care.

About one patient in ten is harmed while receiving acute care and about $30-50 \%$ of these events are preventable. This issue is not only related to hospitals, in fact it is estimated that four patients out of ten are harmed in primary care and outpatient settings and, in these contexts, about $80 \%$ of events are preventable. Moreover, this problem affects both high-income and low- and middle-income countries. 
The burden of this issue also affects economic resources. The Organisation of Economic Co-operation and Development (OECD) has estimated that adverse events engender $15 \%$ of hospital expenditures and activities. For all these reasons, investments in patient safety are necessary to improve patient outcomes and to obtain financial savings which could be reinvested in healthcare. Prevention expenditures are lower than treatment ones and they add important value to the national healthcare systems.

\subsection{Most Frequent Adverse Events}

Adverse events affect patients in all the various steps of care, in both acute and outpatient settings, and they are transversal globally. Although priorities differ according to the characteristics of each country and its healthcare system, it is essential to support the management of clinical risks to ensure safety of care.

Below are brief descriptions of the main patient safety issues and the burden each represents worldwide, as identified by the World Health Organization.

\subsubsection{Medication Errors}

A medication error is an unintended failure in the drug treatment procedure which could harm the patient. Medication errors can affect all steps of the medication process and can cause adverse events most often relating to prescribing, dispensing, storage, preparation, and administration. The annual combined cost of these events is one of the highest, an estimated 42 billion USD.

\subsubsection{Healthcare-Associated Infections}

Healthcare-associated infections are the infections that occur in patients under care, in hospitals or in another healthcare facilities, and that were not present or were incubating at the time of admission. They can affect patients in any type of care setting and can also first appear after discharge. They also include occupational infections of the healthcare staff. The most common types of healthcare-associated infections are pneumonia, surgical site infections, urinary tract infections, gastro-intestinal infections, and bloodstream infections. In acute care settings, the prevalence of patients having at least one healthcare-associated infection is estimated to be around 7\% in high-income countries and $10 \%$ in low- and middle-income countries, while prevalence in long-term care facilities in the European Union is about 3\%. Intensive care units (ICU) have the highest prevalence of healthcare-associated infections worldwide, ICU-associated risk is 2-3 times higher in low- and middle-income countries than in high-income ones; this difference also concerns the risk for newborns which is 3-20 times higher in low- and middle-income countries.

\subsubsection{Unsafe Surgical Procedures}

Unsafe surgical procedures cause complications for up to $25 \%$ of patients. Each year almost 7 million surgical patients are affected by a complication and about 1 million die. Safety improvements in the past few years have led to a decrease in deaths related to complications from surgery. However, differences still remain between lowand middle-income countries and high-income countries; in fact, the frequency of adverse events is three times higher in low- and middle-income countries.

\subsubsection{Unsafe Injections}

Unsafe injections can transmit infections such as HIV and hepatitis B and C, endangering both patients and healthcare workers. The global impact is very pronounced, especially in low- and middle-income countries where it is estimated that about 9.2 million disability-adjusted life years (DALYs) were lost in the 2000s. 


\subsubsection{Diagnostic Errors}

A diagnostic error is the failure to identify the nature of an illness in an accurate and timely manner and occurs in about $5 \%$ of adult outpatients. About half of these errors can cause severe harm. Most of the relevant data concern high-income countries but diagnostic errors are also a problem for low- and middle-income countries, mainly related to limited access to care and diagnostic testing resources.

\subsubsection{Venous Thromboembolism}

Venous thromboembolism is one of the most common and preventable causes of patient harm and represents about one third of the complications attributed to hospitalization. This issue has a significant impact both in the high-income countries, where 3.9 million cases are estimated to occur yearly, and in low- and middle-income countries, which see about 6 million cases each year.

\subsubsection{Radiation Errors}

Radiation errors include cases of overexposure to radiation and cases of wrong-patient and wrongsite identification. Each year, more than 3.6 billion X-ray examinations are performed worldwide, of which $10 \%$ are performed on children. Additionally, other types of examinations involving radiation are frequently performed, such as nuclear medicine (37 million each year) and radiotherapy procedures $(7.5$ million each year). Adverse events occur in about 15 cases per 10,000 treatments.

\subsubsection{Unsafe Transfusion}

Unsafe transfusion practices expose patients to the risk of adverse transfusion reactions and transmission of infections. Data on adverse transfusion reactions from a group of 21 countries show an average incidence of 8.7 serious reactions per 100000 distributed blood components.

\subsection{Implementation Strategy}

Through the years, some progress has been made in raising awareness of practices that support patient safety. For example, in 2009 the European Union issued the "Council recommendation on patient safety, including the prevention and control of healthcare-associated infections (2009/C 151/01)" and in 2012 it launched the "European Union Network for Patient Safety and Quality of Care, PaSQ" a network that aims to improve safety of care through the sharing of information and experience, and the implementation of good practices.

In many countries, support of patient safety practices has developed through the establishment of national plans, networks, and organizations; moreover, some countries, such as the United States, Australia, and Italy, have also enacted national laws on the topic.

In 2019, an important landmark resolution (WHA72.6) 'Global action on patient safety' was adopted by the 194 countries that participated in the 72nd World Health Assembly held in Geneva. Based on the common agreement that this matter is a major global health priority, a whole day was dedicated to its discussion. As a result, the 17th of September 2019 became the first "World Patient Safety Day." Every year, this day will be dedicated to promoting public awareness and engagement, enhancing global understanding, and spurring global solidarity and action. The aim is to engage all the categories of people involved in providing care: patients, healthcare workers, policymakers, academics, and researchers, as well as professional networks and healthcare industries.

\subsection{Recommendations and Future Challenges}

Some progress has been made in addressing patient safety issues since 1999, but in order to overcome this challenge it is important to implement a system that guarantees daily safety measures in all care settings and that involves all stakeholders, including both healthcare professionals and patients. 
First of all, it is important to promote transparency around events that have led to harm and open disclosure with the patient, their family, caregivers, and other support persons. At the same time, it is necessary to encourage public awareness of the measures taken by healthcare organizations for the prevention of adverse events. This need is underlined by the result of a Eurobarometer survey that found that European citizens perceive the risk of being harmed during care to be higher than in reality, both in hospitals and in non-acute settings-in fact more than half of the respondents believed that they could be harmed while receiving care. The model of patient care should switch from a "patientcentered" approach to a "patient-as-partner" approach that establishes direct and active participation in ensuring one's own safety in care: the patient should become a member of the healthcare team.

It is necessary to reaffirm the idea that patient safety is not in the hands of one professional in particular, but in the hands of each healthcare worker. All healthcare organizations have the unavoidable duty to introduce and support the training of all healthcare workers in specific matters of safety.

The probability of making mistakes decreases when the environment is designed with error prevention in mind, incorporating well-structured tasks, processes, and systems. For the continuous improvement, healthcare systems must have immediate access to information that supports learning from experience in order to identify and implement measures that prevent error. Therefore, healthcare systems must dispense with the "blame and shame" culture which prevents acknowledgment of errors and hampers learning and must promote a "safety culture" which allows insight to be gained from past errors. A safety culture can only be established in an open and transparent environment and only if all levels of the organization are involved. In this context, an efficient reporting system should be a cornerstone for healthcare organizations, collecting experiences and data (e.g., of adverse events and near misses) and providing feedback from professionals. In addition, it is essential to guarantee support for professionals involved in adverse events; the "second victims" of an adverse event are healthcare workers who might have been emotionally traumatized. Without adequate support, a second victim experience can harm the emotional and physical health of the involved professional, generate self-doubt regarding their clinical skills and knowledge, reduce job satisfaction to the point of wanting to leave the healthcare profession, and, as a result of all these issues, can affect patient safety.

Another area for improvement is the synergy between patient safety, safety allied programs, health and clinical program and healthcare activities such as accreditation and management of quality of care. Therefore, regardless of the way such functions are structured within countries and healthcare organizations, the branches of patient safety, safety allied programs and quality of care must collaborate to identify common priorities, tools, actions, and indicators to align efforts and enhance outcomes.

The needs brought about by the international movement of people and the differences in safety priorities across the globe have focused the attention on the importance of an international, common strategy for patient safety. To this end, strong commitment is needed from the major international healthcare organizations for the creation of international networks and the sharing of knowledge, programs, tools, good practices, and benchmarking according to standardized indicators. Thus, the global strategy for patient safety must involve three distinct steps. The first step is to secure strong international commitment, including both high-income and low- and middle-income countries, with particular emphasis on those which have not yet been involved, especially in the low- and middle-income group. The second step is to focus on specific patient safety issues that depend on local context and require tailored solutions. The third step is to coordinate between all stakeholders to optimize impacts, avoid the duplication of efforts, and pool programs, strategies, and tools. It is also essential to identify trends and recurring issues and evaluate shared indicators. This strategy should form part of a "glocal" approach 
adopted by all countries, regions, and healthcare organizations: the selection of specific actions tailored on the particularity of each context, while benefitting from the new level of collaboration, knowledge, and opportunities afforded by globalization.

\section{Bibliography}

1. Institute of Medicine (US) Committee on Quality of Health Care in America, Kohn LT, Corrigan JM, Donaldson MS. To err is human: building a safer health system. Washington, DC: National Academy Press (US); 2000.

2. Global priorities for patient safety research. Geneva: World Health Organization; 2009. Available from: http://apps.who.int/iris/bitstream/handle/10665/44205/9789241598620_eng.pdf;jsessionid $=86 \mathrm{~A} 5928 \mathrm{D} 299 \mathrm{~B} 2 \mathrm{CC} 2 \mathrm{~B} 9 \mathrm{EBAA} 241 \mathrm{~F} 34663 \mathrm{D}$ ? seque nce $=1$. Accessed 10 Feb 2020 .

3. Quality of care: patient safety. Report by the Secretariat (A55/13), Geneva: World Health Organization; 2002. Available from: https://www.who.int/patientsafety/ worldalliance/ea5513.pdf?ua=1\&ua=1. Accessed 10 Feb 2020.

4. Slawomirski L, Auraaen A, Klazinga N. The economics of patient safety: strengthening a value-based approach to reducing patient harm at national level. Paris: OECD; 2017. Available from: http://www.oecd. org/els/health-systems/The-economics-of-patientsafety-March-2017.pdf. Accessed 14 Feb 2020.

5. Patient safety-global action on patient safety. Report by the Director-General. Geneva: World Health Organization; 2019. Available from: https://apps. who.int/gb/ebwha/pdf_files/WHA72/A72_26-en.pdf. Accessed 13 Feb 2020.

6. Patient safety in developing and transitional countries. New insights from Africa and the Eastern Mediterranean. Geneva: World Health Organization; 2011. Available from: http://www.who.int/patientsafety/research/emro_afro_report.pdf?ua=1. Accessed 12 Feb 2020.

7. Wilson RM, Michel P, Olsen S, Gibberd RW, Vincent C, El-Assady R, et al. Patient safety in developing countries: retrospective estimation of scale and nature of harm to patients in hospital. BMJ. 2012;344:832.

8. Slawomirski L, Auraaen A, Klazinga N. The economics of patient safety in primary and ambulatory care: flying blind. Paris: OECD; 2018. https://doi. org/10.1787/baf425ad-en. Accessed 10 Feb 2020.

9. Atken M, Gorokhovich L. Advancing the responsible use of medicines: applying levers for change. Parsippany, NJ: IMS Institute for Healthcare Informatics; 2012. Available from: http://papers. ssrn.com/sol3/papers.cfm?abstract_id=2222541. Accessed 13 Feb 2020.
10. WHO global patient safety challenge: medication without harm. Geneva: World Health Organization; 2017. Available from: http://apps.who.int/iris/bitstream/10665/255263/1/WHO-HIS-SDS-2017.6-eng. pdf?ua=1\&ua=1. Accessed 11 Feb 2020.

11. Report on the burden of endemic health careassociated infection worldwide. Geneva: World Health Organization; 2011. Available from: http://apps.who.int/iris/bitstream/ handle/10665/80135/9789241501507_eng. pdf? sequence=1. Accessed 14 Feb 2020.

12. Suetens C, Latour K, Kärki T, Ricchizzi E, Kinross P, Moro ML, et al. Prevalence of healthcare-associated infections, estimated incidence and composite antimicrobial resistance index in acute care hospitals and long-term care facilities: results from two European point prevalence surveys, 2016 to 2017. Euro Surveill. 2018;23(46):1800516.

13. WHO guidelines for safe surgery 2009: safe surgery saves lives. Geneva: World Health Organization; 2009. Available from: http://apps.who.int/iris/bitstream/handle/10665/44185/9789241598552_eng. pdf?sequence=1. Accessed 10 Feb 2020.

14. Bainbridge D, Martin J, Arango M, Cheng D. Perioperative and anaesthetic-related mortality in developed and developing countries: a systematic review and meta-analysis. Lancet. 2012;380(9847):1075-81.

15. Hauri AM, Armstrong GL, Hutin YJ. The global burden of disease attributable to contaminated injections given in healthcare settings. Int J STD AIDS. 2004;15(1):7-16.

16. Singh H, Meyer AN, Thomas EJ. The frequency of diagnostic errors in outpatient care: estimations from three large observational studies involving US adult populations. BMJ Qual Saf. 2014;23(9):727-31.

17. Khoo EM, Lee WK, Sararaks S, Samad AA, Liew SM, Cheong AT, et al. Medical errors in primary care clinics - a cross sectional study. BMC Fam Pract. 2012;26(13):127.

18. National Academies of Sciences, Engineering, and Medicine. Improving diagnosis in health care. Washington, DC: National Academies Press; 2015. Available from: https://www.ncbi.nlm.nih.gov/ books/NBK338596/pdf/Bookshelf_NBK338596.pdf. Accessed 10 Feb 2020.

19. Singh H, Graber ML, Onakpoya I, Schiff G, Thompson MJ. The global burden of diagnostic errors in primary care. BMJ Qual Saf. 2017;26(6):484-94.

20. Clinical transfusion process and patient safety: aidemémoire for national health authorities and hospital management. Geneva: World Health Organization; 2010. Available from: http://www.who.int/bloodsafety/clinical_use/who_eht_10_05_en.pdf?ua=1. Accessed 14 Feb 2020.

21. Janssen MP, Rautmann G. The collection, testing and use of blood and blood components in Europe. Strasbourg: European Directorate for the Quality of Medicines and HealthCare (EDQM) of the Council of Europe; 2014. Available from: https://www.edqm. 
eu/sites/default/files/report-blood-and-blood-components-2014.pdf. Accessed 10 Feb 2020.

22. Boadu M, Rehani MM. Unintended exposure in radiotherapy: identification of prominent causes. Radiother Oncol. 2009;93:609-17.

23. Global initiative on radiation safety in healthcare settings. Technical meeting report. Geneva: World Health Organization; 2008. Available from: http://www.who. int/ionizing_radiation/about/GI_TM_Report_2008_ Dec.pdf. Accessed 10 Feb 2020.

24. Shafiq J, Barton M, Noble D, Lemer C, Donaldson LJ. An international review of patient safety measures in radiotherapy practice. Radiother Oncol. 2009;92:15-21.

25. Fleischmann C, Scherag A, Adhikari NK, Hartog CS, Tsaganos T, Schlattmann P, et al. Assessment of global incidence and mortality of hospital-treated sepsis. Current estimates and limitations. Am J Respir Crit Care Med. 2016;193(3):259-72.

26. Leape L. Testimony before the President's Advisory Commission on consumer production and quality in the health care industry, 19 Nov 1997.

27. Workplace Health and Safety Queensland. Understanding safety culture. Brisbane: The State of Queensland; 2013. Available from: https://www.worksafe.qld.gov.au/_data/assets/pdf_file/0004/82705/ understanding-safety-culture.pdf. Accessed 13 Feb 2020.

28. Yu A, Flott K, Chainani N, Fontana G, Darzi A. Patient safety 2030. London: NIHR Imperial Patient Safety Translational Research Centre; 2016.

29. Special Eurobarometer 411 "Patient safety and quality of care". Available from: https://ec.europa. eu/commfrontoffice/publicopinion/archives/ebs/ ebs_411_en.pdf. Accessed 13 Feb 2020.

30. Karazivan P, Dumez V, Flora L, et al. The patientas-partner approach in health care: a conceptual framework for a necessary transition. Acad Med. 2015;90(4):437-41.

31. Donabedian A. Explorations in quality assessment and monitoring, The definition of quality and approaches to its assessment, vol. 1. Ann Arbor, MI: Health Administration Press; 1980.

32. Council Recommendation of 9 June 2009 on patient safety, including the prevention and control of healthcare associated infections. Official Journal of the European Union, C 151, 3 July 2009. Available from: https://eur-lex.europa.eu/legal-content/EN/ TXT/?uri=uriserv:OJ.C_.2009.151.01.0001.01. ENG\&toc=OJ:C:2009:151:TOC. Accessed 11 Feb 2020.

33. European Union Network for Patient Safety and Quality of Care, PaSQ Joint Action. Available from: http://pasq.eu/Home.aspx. Accessed 11 Feb 2020.

34. Patient safety and quality improvement act of 2005. Available from: https://www.govinfo.gov/content/ pkg/PLAW-109publ41/pdf/PLAW-109publ41.pdf. Accessed 14 Feb 2020.

35. National Health Reform Act 2011. Available from: https://www.legislation.gov.au/Details/ C2016C01050. Accessed 14 Feb 2020.

36. Legge 8 marzo 2017 n.24. GU Serie Generale n.64 del 17-03-2017. Available from: https://www.gazzettaufficiale.it/eli/id/2017/03/17/17G00041/sg. Accessed 14 Feb 2020.

Open Access This chapter is licensed under the terms of the Creative Commons Attribution 4.0 International License (http://creativecommons.org/licenses/by/4.0/), which permits use, sharing, adaptation, distribution and reproduction in any medium or format, as long as you give appropriate credit to the original author(s) and the source, provide a link to the Creative Commons license and indicate if changes were made.

The images or other third party material in this chapter are included in the chapter's Creative Commons license, unless indicated otherwise in a credit line to the material. If material is not included in the chapter's Creative Commons license and your intended use is not permitted by statutory regulation or exceeds the permitted use, you will need to obtain permission directly from the copyright holder. 